\title{
THERMAL AND STRUCTURAL ANALYSIS OF RING COMPONENTS BY THE FINITE ELEMENT METHOD*
}

BNL --36573

DE85 013305
Rodulfo Alforque, and Sushil Sharms Netional Synchrotron Light Source Brookhaven National Laboratory Upton, New York 11973

\section{INTRODUCTION}

In a previous report $[1]$, a thermal otudy was made in order to determine the effects of a ohift in the electron vertical orbital plene, and the resulting dinplacement of the wiggler photon beam otriking the inner surface of the vacuum chamber. Since then, due to some changes in the physical parameters of the vacuum chamber, new design had been developed. The new geometry is quite different from the one described in [1], due primarily to an increase in the chamber vertical aperturt which was opened to $23 \mathrm{~mm}$. from an initial opening of $6 \mathrm{~mm}$.

Subsequently, new study was conducted for this new chamber design that included a structural analysis in order to determin 'sie stresses and deflections of the vacuum charnt - dup to the combined th rimal and mechanical los jing. It ohould be noted the various geometrical modele ivere analyzed before $t\}$ c final geometry was decided. This report will only describe in detail the results of the thermal and structural analysis of the final geometry using the finite element code, ANSYS $\mid 3$;.

\section{FINITE ELEMENT MODEL}

The region of interest in the vacuum chamber was dereloped into a 2-dimensional finite element mesh. A fine mesh was used in the region where the gaussiandistributed heat load was applied in order to achieve a more accurate approximation. The full finite element model cnnsisted of a total of 397 elements.

The chambe: is made of silicon-megnesium aluminum alloy similar to 6063-T5 but stress relieved tu a yield strengtb of 23 ksi. The areas of particular interest in this chamber were the inner ourface exposed to the photon beam, and the cooling channel wall. The inner surface should not resch temperatures beyond the corresponding yield point of the material and the cool ing channel wall temperatures should not be at levels that could initiate nucleate boiling caused by localized heating.

The element type that was used in the thermal model was a 2-D isoparametric thermal solid. The thermal run would produce the temperature distribution over the whole model. This distrjbution is then passed to the structural model for the subsequent stress and deflections andysis; The thermal element, Stif55, was converted into a $2-\mathrm{D}$ isoparametric solid structural element, Stif42, for the structural portion of the aralysis.

* Work performed under the auspices of the U.S. Department of Energy.
The actual geometry of the vucuum chamber is to complex that it is very difficult to predict accurately the uctual utresses. Two structural models have been used, however, in order to bracket the possible state of stress during machine operation. The two andytical models are:

\section{a) Plane Strese Model}

This model gives the lower bound of the state of stress of the vacuum chamber. This essumes no restraint in the $\mathrm{s}$-direction thereby allowing full extension in that direction with no resulting stresses; The prevailing load is the pressure load.

b) Plane Strain Model

The atresses from this model represent the worst possible state of stress that can occur in the chamber. The z-direction strain is zero, implying a rigid restraint in thet direction thus causing a high stress, $S_{z}$, primarily due to the thermol losd.

\section{LOADS AND BOUNDARY CONDITIONS}

At full power, i.e. $E=2.5 \mathrm{Gev}, \& \mathrm{I}=500 \mathrm{ma}$, and with a vertical dieplacement $y \mathrm{~mm}$, the power density, $P(y)$, at source distance, $D=10 \mathrm{~m}$., can be expressed as [see ref. 2]:

$$
P(y)=88.72 F(\gamma \varphi)
$$

where,

$$
F(\gamma \varphi)=0.4375 e^{-\frac{2}{1}\left(\frac{0}{0} \cot 601\right)^{3}}
$$

The maximum power density on the vacuum chamber ourface occurs at an engie of $9.16^{\circ}$ to the surface and at a distace, $D=6.40 \mathrm{~m}$., from the source $[1]$. The beam power density striking the chamber at this distance is:

$$
P_{1}(y)=\left(\frac{10}{6.49}\right)^{2} P(y)
$$

Integrating eq. (2) over the vertical spectrum gives the heat carried by the photon beam. The component of this heat absorbed by the vacuum chamber is :
$P_{T}=2 \int_{0}^{\infty} P_{1}(y) \sin 9.16^{\circ} d y$ 


\section{DISCLAIMER}

This report was prepared as an account of work sponsored by an agency of the United States Government. Neither the United States Government nor any agency thereof, nor any of their employees, makes any warranty, express or implied, or assumes any legal liability or responsibility for the accuracy, completeness, or usefulness of any information, apparatus, product, or process disclosed, or represents that its use would not infringe privately owned rights. Reference herein to any specific commercial product, process, or service by trade name, trademark. manufacturer, or otherwise does not necessarily constitute or imply its endorsement, recommendation, or favoring by the United States Government or any agency thereof. The views and opinions of authors expressed herein do not necessarily state or reflect those of the United States Government or any agency therenf. 
If the chamber intercepts the full vertical width of the beaw at full power $(I=600 \mathrm{ma})$, the power abnorbed by the therioal model is 30 watts per mm. of chnmber length. This power was distributed to 19 nodal points in an approximately saussian distribution, and cix load cases were etudied; The 6th load case simulated partial but most of the beam striking the vacuum chamber.

In addition, load cases 5 and 6 were run with varying besm current from 100 to 500 mo. In all caises, heat removal was achieved by applying a convective boundary condition along the wall of the cooling chonnel.

Fig.l shows some relevant parameters regarding the loads and boundary conditions. The structural model was given symmetry boundary condition at eppropriste areas. A pressure load of $14.7 \mathrm{psi}$ was applied along all surfaces exposed to the atmosphere and an average water pressure of 70 psi was applied to the elements along the wetted perimeter of the cooling channel.
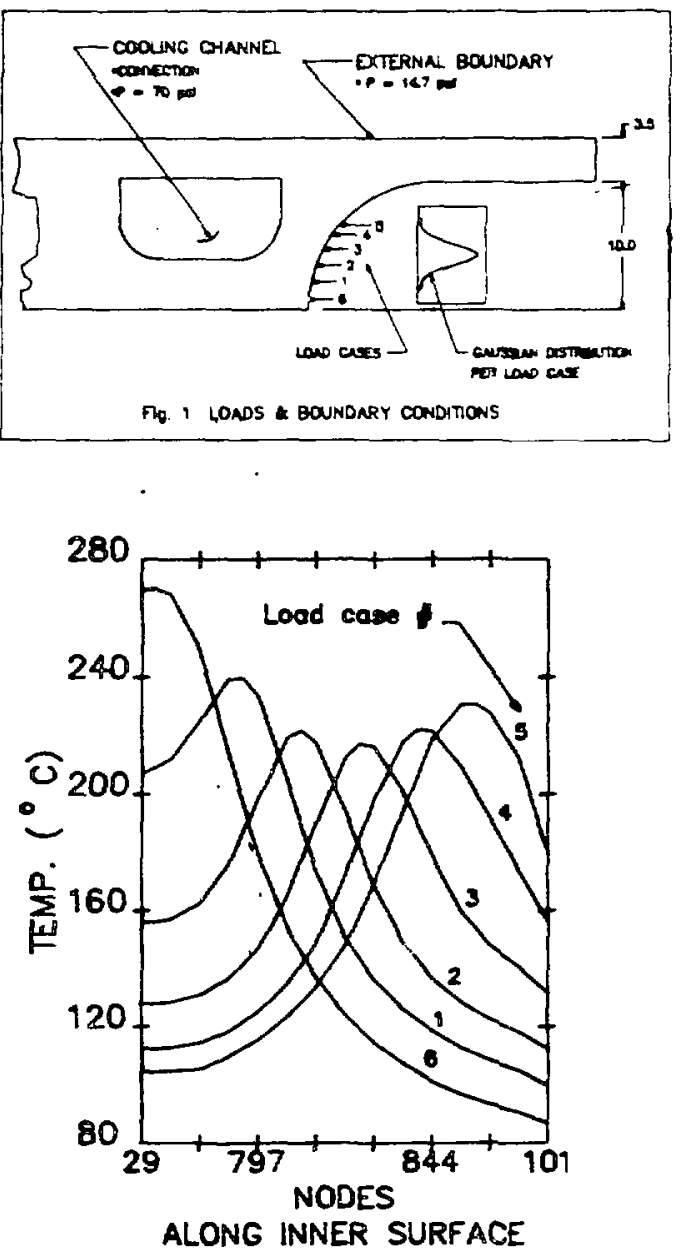

Fig.2: SURFACE TEMPERATURES

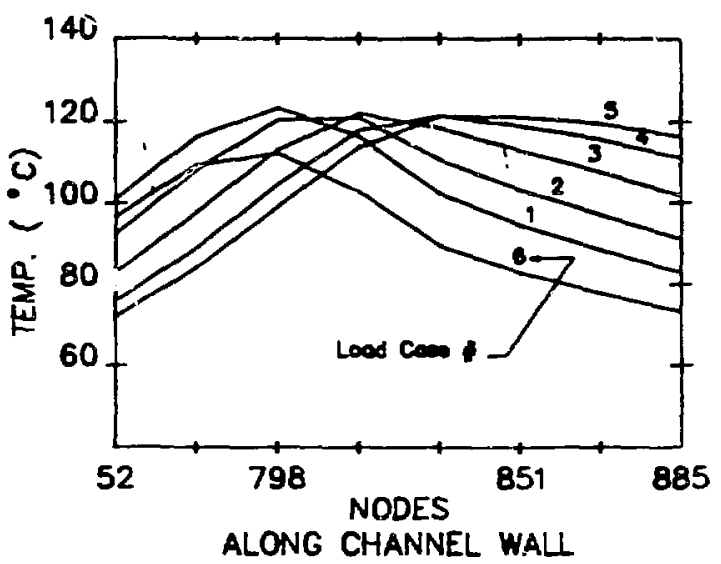

Fig.3: CHANNEL WALL TEMP.

\section{RESULTS}

\section{a) Thermal Model}

The results of a steady atate solution of the thermal modal at full power for the six load cases are shown in Figs.2,\& 3. The inner surface of the vacuum chamber would reach a maximum of $270^{\circ} \mathrm{C}$ which is the peak temperature for load case 6 . This temperature is well below the melting point of aluminum which is $615^{\circ} \mathrm{C}$.

At full power, the cooling channel wall will attain a maximum of $123^{\circ} \mathrm{C}$. This corresponds to about 30 psia saturation pressure for water, hence if the cooling water is maintained well above 30 psis no nucleate boiling could begin. The total pressure drop required along the cooling channel is about 20 psi, and since the available supply pressure of the cooling water is $90 \mathrm{psi}$, there is ample factor of safety to avoid boiling within the channe! even at full power.

\section{b) Plane Stress Model}

The maximum deflection along the $y$-axis is about $0.175 \mathrm{~mm}$. and this occurs, as expected, along $A-A$ in Fig. 1. There is very little variation in the stresses and deflections for the six load cases, since obviously, the dominant structural loading is the pressure load. The maximum stress intensity, which is about $4.7 \mathrm{ksi}$ for load case 6 is not of critical concern since the temperatures there are low enough that the material strength are still very nearly room temperature values. However, in load case 5 , the region where the highest temperature occurs deserves some examination. This temperature is $231^{\circ} \mathrm{C}$ and the corresponding yield strength of the material at this temperature is about $5 \mathrm{ksi}$. The stress intensity at this node is about 2.7ksi. Obviously, the factor of safety in this situation is only roughly 2 . Fig. 4 is a typical stress contour plot. 


\section{REFRODUCED FROM BEST AVAILABLE COPY}

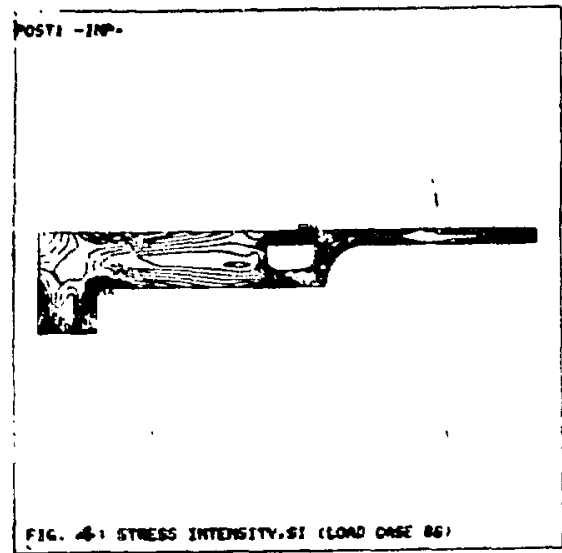

$\max$

10. If. Si: Gita: Iithes mor II wore fiatine Dist-E.:$5-5.5$ $7 \cdot 12$. exposing incolice

\section{c) Plane Strain Model}

Although the deflections $\left(U_{v}\right)$ are essentially the same as in (b), the stresses are quite high when the plane strain boundary condition is imposed. These defiections, however, do not include the effects of the bending moments due to the chamber supports. Therefore, we decided to run the analysis at increasing besm eurrents starting from $I=100$ ms at the anme beam energy. For each run, the thermal parameters, ouch as the bulk water temperature and the film coefficient, were modified to reflect the corresponding heat loading. Fig. 5 summarizes the temperstures and atress iniensities along the inner surface of the chamber. In' zed, as the beam current goes beyond 200 ma the str' i levels will exceed the corresponding yield point. Beyond the yield point, however, the corresponding stress intensities are -o longer realistic since the solution presented here is biused on a linear, elastic formulation.

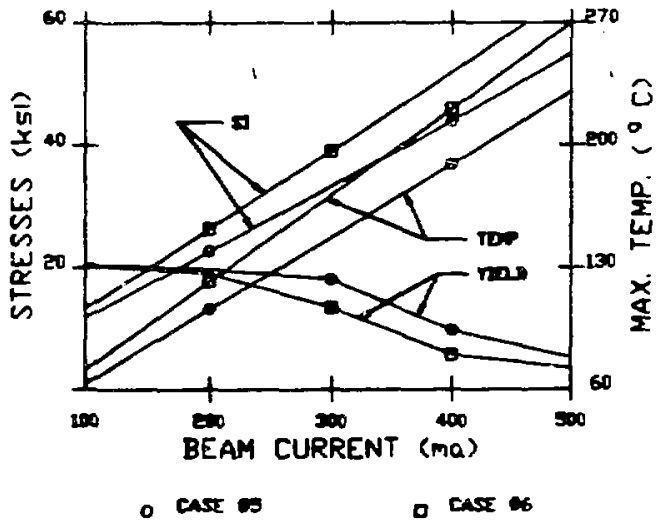

FIg.5: PLANE STRAIN MDDEL

\section{CONCLUSIONS}

In view ot the above renults, when the plane streas boundary condition are applicable, the recuum cham. bes deaign look accepsable even at full power. On the other hand, when there in abolute bxity in the z-direction, i.e., the plane atrain beundery condition exists, operation above $200 \mathrm{me}$ neeme seriously questionable. It is obrious that material yieldins will occur at higher currents, and permanent material set can happen thet may compromise the structural integrity of the affected areas. We have mentioned at the outcet that the actud condition can be bracieted by the plane-stress/plent-atrain models; Unfortunately, however, dye to various restraints along the length of the chamber, the real case is closer to a plane atrain aituation. Since this andysis is based on a linear, elastic F.-mulation and the atreases are greater than the yield point at highe: currents, it might be useful to look at the situation more closely using the non-linear approach.

In closing, we would like to mention that work is continuing on the numerical andysis of the water-ccoled beam stop that sits inside the vacuum chamber. Fig. 6 shows the $3-D$ finite element mesh,but we are unable to present the results of such aralysis in this paper, however.

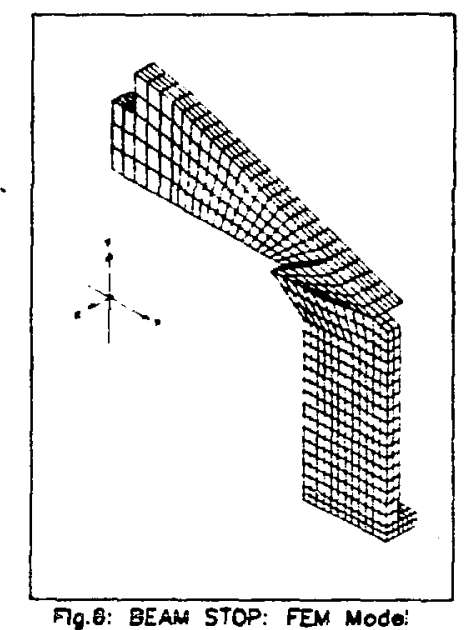

\section{REFERENCES}

1) Vacuum Ring Exit Chamber Temperatures Due to Wiggler Beam Heating, S. Sharma and S. Ule, BNL34314, January, 1884

2) X-Ray Power Distribution From Multipole Wiggler Magnets, W. Thomlinson, NSIS Internal Report, April 1983

3) ANSYS, General Purpose Finite Element Code, Swanson Analysis Systems Ine., Houston, PA 15342

\section{ACKNOWLEDGEMENT}

We are grateful to Bark Bsich and Sam Krinsky for their heipful suggestions and discussions during the course of this work. 